\title{
¿Es posible realizar un grafiti en un bien de interés cultural? A propósito del caso PichiAvo
}

Francisca Ramón Fernández | Dpto. de Urbanismo, Universitat Politècnica de València

URL de la contribución <www.iaph.es/revistaph/index.php/revistaph/article/view/4858>

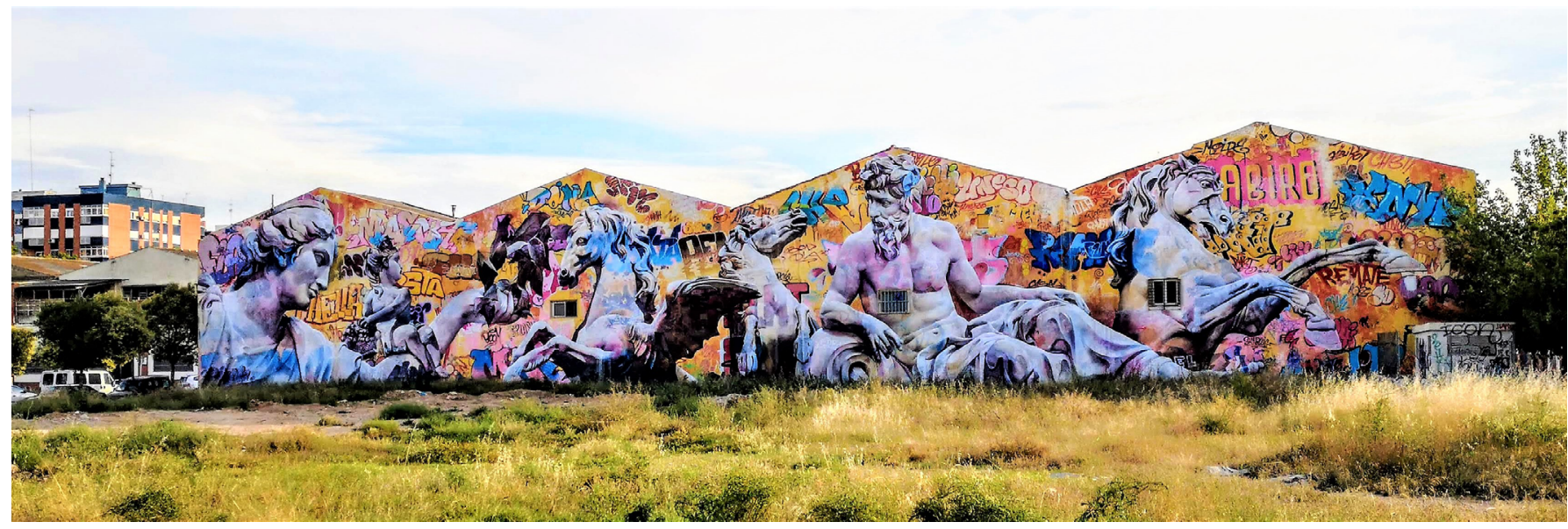

Mural de PichiAvo en Ciudad Fallera, Valencia | foto Antonio Marín Segovia

\section{El grafiti: algunas consideraciones}

La Real Academia Española define el grafiti como "Firma, texto o composición pictórica realizados generalmente sin autorización en lugares públicos, sobre una pared u otra superficie residente", pero no alude a su valor artístico o creativo.

El grafiti ha sido denostado por la legislación que, lejos de ampararlo, lo ha sancionado y multado, como se establecía en los preceptos, actualmente derogados, del Código Penal (Armas 2019).

El grafiti, como expresión cultural, ha estado asociado a la cultura de la calle, a la protesta social y a la reivindicación del espacio común para manifestar el arte de la colectividad.

Han sido distintos casos que el grafiti ha superado al autor y se ha convertido en un emblema social. No hay que olvidar el caso de Muelle cuya firma con incorporación de una flecha correspondía a Juan Carlos Argüello
Garzo, y la restauración de uno de sus grafitis en la calle Montera, de Madrid. O el caso de Banksy, cuyas obras se plasman en el ámbito urbano, por citar alguno de ellos.

El grafiti siempre ha necesitado su espacio, y no siempre lo ha encontrado. De ser considerado como un arte, por algunos, a ser criticado precisamente por su ausencia del mismo. No hay una postura unánime. En la legislación, tampoco. Ha sido siempre el omitido en la normativa, y no ha sido posible introducirlo dentro de las manifestaciones artísticas, quizás por falta de interés en que se asemejara a las diversas Bellas Artes que sí que tenían hueco en la legislación.

No obstante, el grafiti como expresión y como obra, independientemente del soporte, que es precisamente en la mayoría de las ocasiones un bien inmueble (pared), sí que encuentra lugar para su protección en la legislación de propiedad intelectual, como obra original del creador de la misma, el autor, y como tal se le reconocen derechos personales y económicos de indudable aplicación. 
La realización de un grafiti "controlado" en un bien de interés cultural (BIC). El caso PichiAvo en el Claustro renacentista del Centro del Carmen (Valencia)

El grafiti normalmente nos lo encontramos en las paredes de las ciudades. Pero ha habido alguna ocasión en que ese grafiti se ha hecho en una pared "protegida", es decir, en un bien de interés cultural (BIC). Nos referimos al caso de PichiAvo y su intervención en el Claustro renacentista del Centro del Carmen, en Valencia.

Se trataba de un grafiti de más de mil metros cuadrados realizado por los dos artistas en el edificio del siglo XIII protegido como BIC, con lo que entra en juego la legislación de patrimonio cultural valenciano.

Sobre la obra se generaron corrientes a favor y en protesta, incluso con interposición de procedimiento judicial (Camacho 2019). A pesar de ser una obra efímera, temporal y reversible se alegaba que no era admisible realizar este tipo de intervención en un BIC, por considerar que no era el lugar apropiado para realizar el grafiti. Se argumentó la intervención como de "inadecuada, inoportuna e imprudente" y también "desafortunada" (Garcés 2019). Junto con ello, se indicaba que esta intervención iba "en contra del espíritu de la ley".

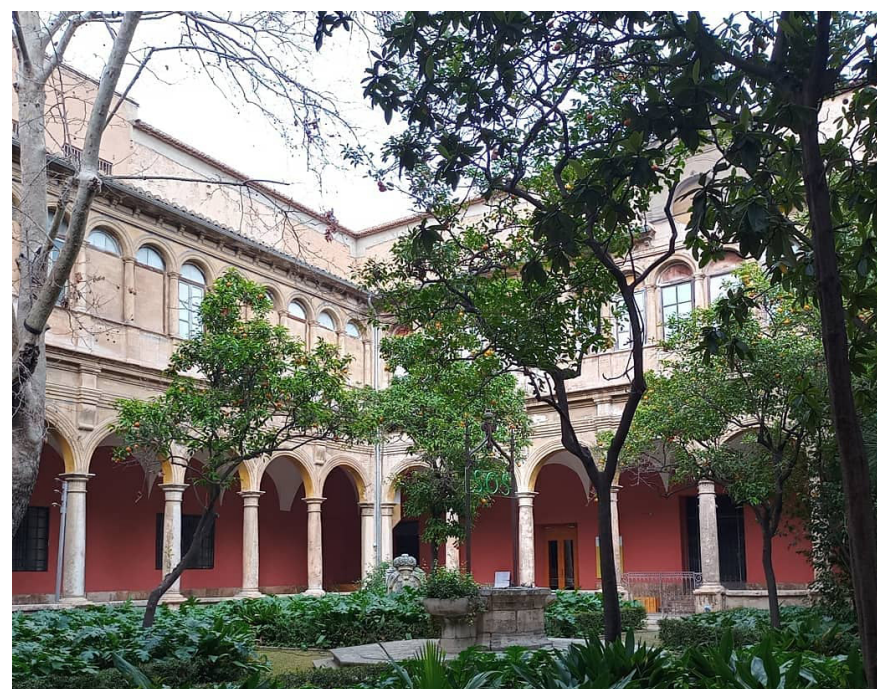

Claustro renacentista del Centro del Carmen | fotos Francisca Ramón Fernández
A efectos legales y en relación con el cumplimiento de la normativa de la legislación de patrimonio valenciana (Ley 4/1998, de 11 de junio), el proyecto no necesitaba, según indicó en su momento la Dirección General de Cultura y Patrimonio, una autorización previa, ya que la intervención carecía de trascendencia patrimonial [art. 35.1,b)] (Camacho 2019); y que, además, las paredes donde se realizó el grafiti se repintaban cada cierto tiempo, con lo que no se trataba de paredes del BIC sin una previa pintura.

La discusión radicaba en considerar si el grafiti era "adecuado" para la ubicación, y si la expresión artística y cultural que se había realizado no hería sensibilidades al ser realizada en un BIC. Si realmente las paredes del claustro se pintan periódicamente con pintura blanca, ¿qué podría molestar que se pudiera realizar un grafiti si después se volvían a pintar las paredes de blanco otra vez? ¿Se considera una falta de respeto hacia el BIC? Creemos que la respuesta puede estar en la obra en sí y no en la pintura. Y desde luego, cuestión muy distinta sería si se hubiera realizado el grafiti sobre paredes en las que no hay repinte, es decir, en la superficie de un bien original, como pueden ser los distintos casos de pintadas que se han producido en otros monumentos

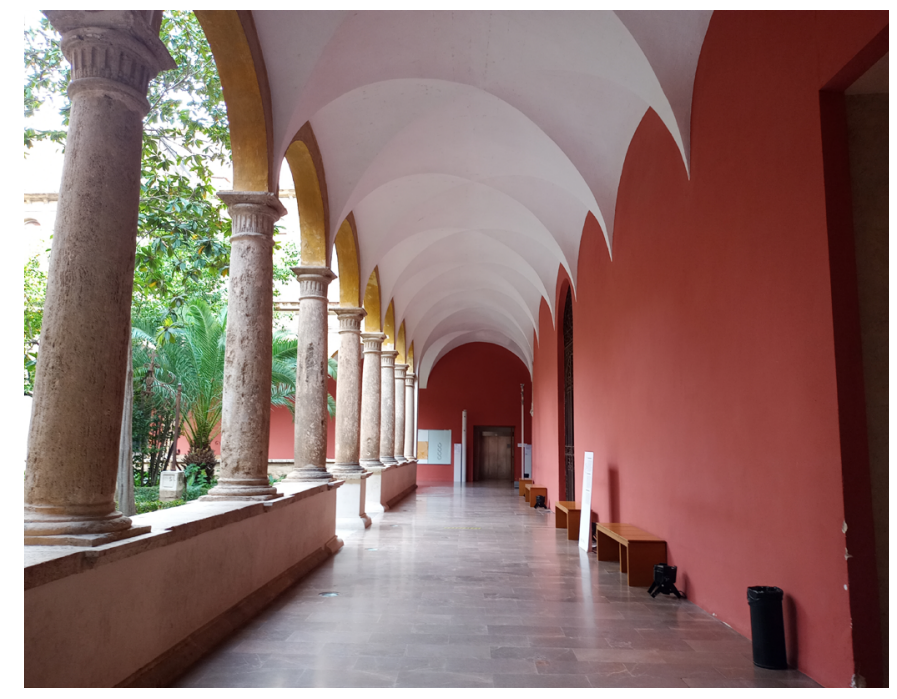




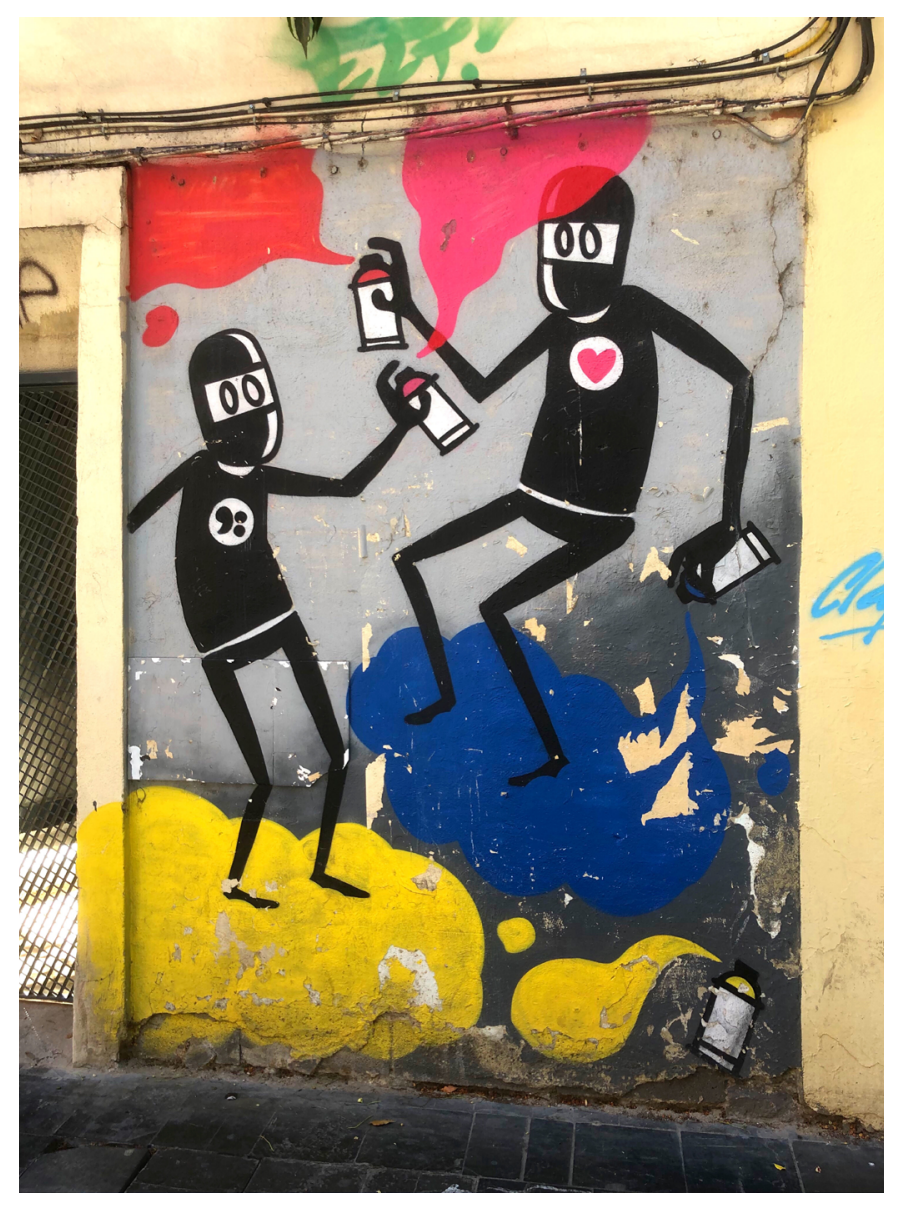

Grafiti.en las calles de Valencia | foto Joan

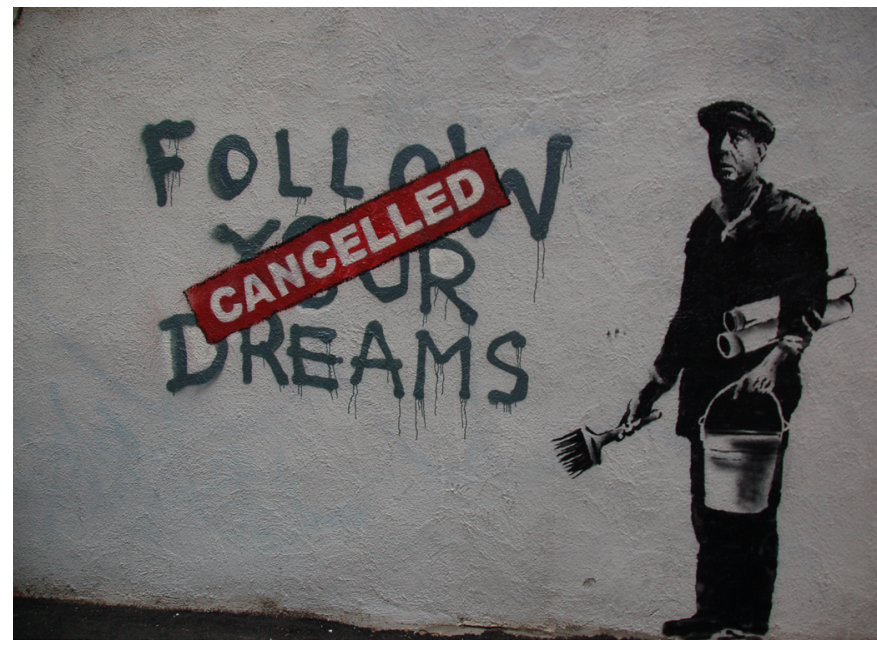

Banksy en Boston | foto Chris Devers protegidos de la ciudad de Valencia, como la Lonja de la Seda, o las Torres de Serranos o de Quart.

Y en cuanto a la aplicación del art. 38.1 que recoge los criterios de intervención en monumentos, esta debe ir "encaminada a la preservación y acrecentamiento de los intereses patrimoniales que determinaron dicho reconocimiento", precepto que sirvió de apoyo para indicar que el grafiti quedaba lejos de considerarse como una actuación para preservar el lugar, además de impedir la contemplación del bien, ya que se ha producido una alteración estética en su visualización (art. 39. 1 e).

Desde luego, el punto de inflexión de la polémica radica en: ¿cuál fue el espíritu o intención de la intervención? Y si se hizo con la finalidad de incrementar el potencial del BIC o con la intención de degradarlo mediante el grafiti. También nos podemos preguntar si la misma polémica se hubiese generado si la obra que se hubiera realizado en el BIC no fuera un grafiti, por sus connotaciones, y hubiera sido una obra de pintura clásica, por ejemplo, que pudiera resultar más aceptable visualmente.

No hay que olvidar tampoco que la consideración como obra de arte del grafiti, como obra, queda protegida por la propiedad intelectual, y también en este caso, en ningún momento, nadie se cuestionó si la creación de PichiAvo, como autores, cuya obra iba a ser destruida después del tiempo fijado, infringía sus derechos de propiedad intelectual.

\section{A modo de conclusión}

El arte urbano y sus connotaciones sociales y culturales supone una expresión cultural (San Juan 2018) que no puede pasar desapercibida por la legislación. Las lagunas y fisuras interpretativas de los preceptos en los que se plantea su admisión o no en ciertas intervenciones debe ser subsanado con una normativa clara y concreta que especifique lo permitido y lo prohibido.

Patrimonio cultural y propiedad intelectual van en distintas ocasiones unidas y no se puede obviar la figura del 
creador, del autor de la obra. Y eso no sólo lo podemos observar en el caso de los bienes muebles e inmuebles, sino también en el ámbito de los distintos soportes que se utilizan para la obra, por ejemplo, una pared en el caso de los grafitis.

La puesta en valor del grafiti pasa por su inclusión en la normativa y su consideración como arte (González 2018), fruto de la originalidad (López 2018) y de la creación del ser humano, en el que se potencia, además, unos valores que representan a una sociedad y en un contexto histórico concreto, la reafirmación de la personalidad del creadorla y la reivindicación a través de la creatividad de necesidades sociales y culturales.

\section{BIBLIOGRAFÍA}

- Armas Pérez, J. (2019) Los grafitis en la legislación española. Derecho y Cambio Social, n. ${ }^{\circ}$ 56, pp. 359-369

- Camacho, N. (2019) Los mil metros de grafiti en el claustro del Centro del Carmen acaban en los juzgados. Las Provincias, 21 de febrero de 2019. Disponible en: https://www. lasprovincias.es/culturas/grafiti-claustro-carmen-juzgados20190221110657-nt.html [Consulta: 03/03/2021]

- Garcés, L. (2019) Expertos consideran que el grafiti del Centro del Carmen bordea la Ley de Patrimonio. Las Provincias, 28 de febrero de 2019. Disponible en: https:// www.lasprovincias.es/culturas/expertos-grafiti-carmen-leypatrimonio-20190228133305-nt.html [Consulta: 03/03/2021]

- González Martín, J.V. (2018) La protección del grafiti como obra de arte. Visual: magazine de diseño, creatividad gráfica y comunicación, 12 diciembre de 2018. Disponible en: http:// visual.gi/la-proteccion-del-grafiti-como-obra-de-arte/ [Consulta: 03/03/2021]

- López Richart, J. (2018) Y el vandalismo se hizo arte: la protección del grafiti por el derecho de autor. RIIPAC: Revista sobre Patrimonio Cultural, n. ${ }^{\circ} 10$, pp. 53-87. Disponible en: https://www.eumed.net/rev/riipac/10/grafiti.pdf [Consulta: 03/03/2021]

- Real Academia Española (2021) Voz "grafiti". Disponible en: https://dle.rae.es/grafiti?m=form [Consulta: 03/03/2021]

- San Juan Fernández, J. (2018) Grafiti y arte urbano: una propuesta patrimonial de futuro. Santander. Estudios de Patrimonio, n. ${ }^{\circ}$ 1, pp. 181-210. Disponible en: https:// santanderestudiospatrimonio.unican.es/index.php/sanespat/ article/view/19 [Consulta: 03/03/2021]

\section{Agradecimientos}

Trabajo realizado en el marco del Proyecto I+D+i "Retos investigación" RTI2018-097354-B-100 (2019-2022) Proyecto de I+D+i Retos MICINN PID2019-108710RB-I00 (2020-2022). 